\title{
Preoperative ethanol sclerotherapy for facial cavernous hemangioma
}

\author{
Y Kenan Coban $\mathrm{MD}^{1}$, Ali Kurt MD ${ }^{2}$ \\ Departments of ${ }^{1}$ Plastic and Reconstructive Surgery, and ${ }^{2}$ Pathology, Numune Hospital, Erzurum, \\ Turkey
}

\section{YK Coban, A Kurt. Preoperative ethanol sclerotherapy for facial cavernous hemangioma. Can J Plast Surg 2001;9(4):159-161.}

Ethanol injection therapy is gaining more acceptance for the treatment of vascular lesions. A case of extensive cavernous hemangioma treated with surgical resection and preoperative sclerotherapy with absolute ethanol is presented. By using magnetic resonance imaging, it was shown that ethanol injections in the vascular channels produced enough sclerosis that excisional surgery with less bleeding was possible.

Key Words: Cavernous hemangioma; Ethanol sclerotherapy; Surgical resection

\section{Sclérothérapie préopératoire à l'éthanol pour un hémangiome caverneux facial}

RÉSUMÉ : Le traitement par injection d'éthanol est de plus en plus accepté dans le cas de lésions vasculaires. On présente ici un cas d'hémangiome caverneux volumineux traité par résection chirurgicale et sclérothérapie préopératoire avec éthanol absolu. L'imagerie par résonance magnétique a mis en évidence le fait que les injections d'éthanol dans les vaisseaux ont provoqué une sclérose suffisamment importante pour rendre possible l'exérèse de l'hémangiome tout en diminuant les pertes sanguines.

$\mathrm{C}$ avernous hemangiomas are deeper in the dermis, and the vascular channels are larger than capillary hemangiomas. These lesions show less tendency toward spontaneous involution. The indications for treatment of cutaneous vascular lesions are disseminated intravascular coagulopathy, high-output cardiac failure, obstruction of body orifices, suspected malignant change, sepsis secondary to disseminated infection, family concern and cosmesis.

Kane et al (1) evaluated hemangiomas and vascular malformations of the head and neck that were larger than $4 \mathrm{~cm}$ in diameter. They treated their patients with sclerotherapy or ablative surgery and found that $77 \%$ of the patients showed good results at seven-year follow-up.

Ablative surgery is very difficult to perform when the cavernous hemangioma is very large. Preoperative embolotherapy or sclerotherapy have been used to reduce bleeding and enhance the ease or effectiveness of resection. One of the treatment modalities for reducing bleeding is intralesional ethanol injection. Percutaneous ethanol injection therapy performed with ultrasonographic or computer tomographic guidance is a steadily growing therapeutic method that can be used in the ablation of solid and cystic masses. Doppman et al (2) injected ethanol into vertebral symptomatic hemangiomas with computer tomographic guidance and reported improvements in $85 \%$ of the patients.

Ethanol sclerotherapy is successfully used in the treatment of vascular malformations, lymphoceles, post-traumatic splenic pseudocyst, portal hypertension and gastrointestinal ulcer bleeding (3-6). Yang et al (7) reported successfully treating a two-year-old girl with KasabachMerrit syndrome for which medical treatment failed with pure ethanol embolotherapy.

\section{CASE PRESENTATION}

An 18-year-old man was referred to the authors' clinic with a mass extending from the right upper lip to the right infraorbital area. Physical examination revealed subdermal palpable hypertrophic enlargement of the right upper lip and a subconjunctival hemangiomatous mass in the conjunctiva of the right lower eyelid (Figure 1A). A magnetic resonance imaging

Correspondence and reprints: Dr Y Kenan Coban, Plastic and Reconstructive Surgery Department, Numune Hospital, Erzurum, Turkey.

Telephone+00 90442 2330363, fax+0090442 3170196, e-mail ykcoban@ixir.com 

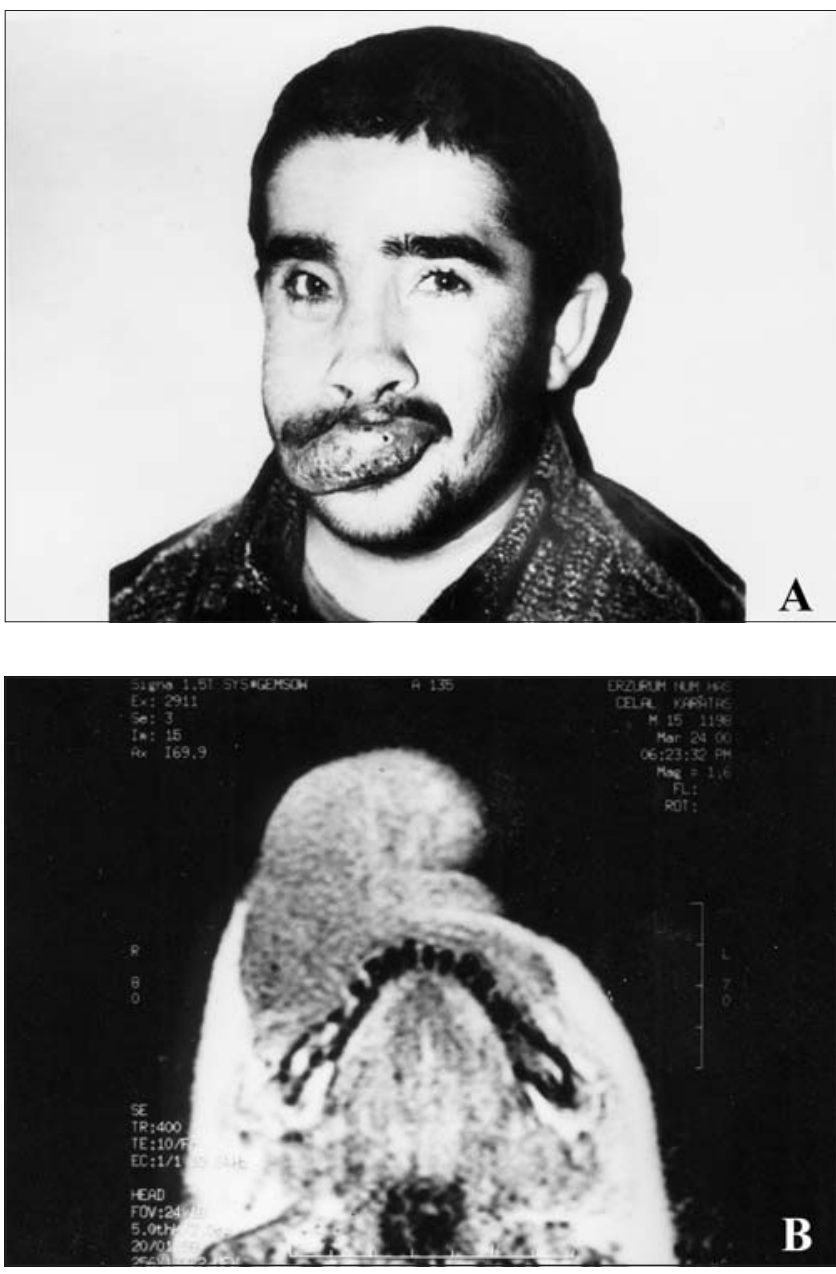

Figure 1) A Preoperative photograph of the patient showing a subdermal palpable hypertrophic enlargement of the right upper lip and a subconjunctival hemangiomatous mass in the conjunctiva of the right lower eyelid. B Magnetic resonance imaging scan of the patient showed a diffusely homogeneous mass in the right infraorbital area

(MRI) scan showed a diffusely homogeneous mass in the right infraorbital area (Figure 1B). Preoperative intralesional ethanol injection was employed once with $40 \mathrm{~mL}$ and once with $50 \mathrm{~mL}$ of absolute alcohol after a 10-day interval. After the last ethanol injection, an MRI scan showed some sclerotic areas in the injection sites of the hemangioma (Figure 2A). The patient was operated on under general anesthesia and ablative surgery was performed. No blood transfusion was needed during the operation and pre- or postoperative hemograms showed minimal blood loss during excisional surgery. The pathological examination of the excisional material revealed mature venous structures and no mature arteriovenous interconnections were identified. Postoperative acceptable aesthetic results were achieved (Figure 2B).

\section{DISCUSSION}

Sclerotherapy with ethanol is an effective and safe method for craniofacial vascular malformations. For extensive perioral malformations, combined sclerotherapy and surgical resection give the best results. Local infiltration or intravascu-
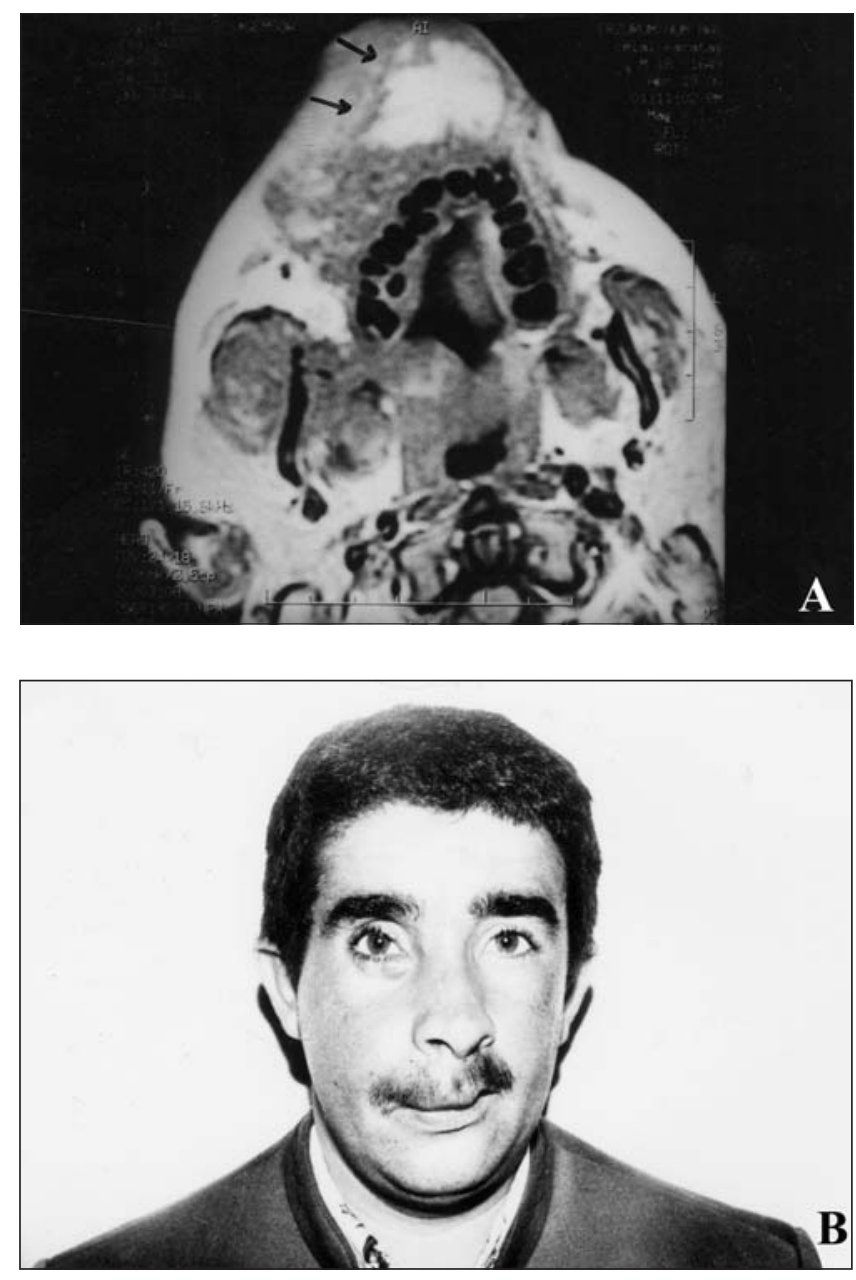

Figure 2) A Magnetic resonance imaging scan showing sclerotic areas (black arrows) one month after the last ethanol injection. B Postoperative photograph of the patient showing acceptable aesthetic results

lar injection of ethanol leads to cell death by causing cell membrane lysis, protein denaturation and vascular occlusion. Mason et al (8) concluded that patients who receive more than $1 \mathrm{~mL} / \mathrm{kg}$ ethanol during sclerotherapy procedures may have elevated serum ethanol levels that could put them at risk of respiratory depression, cardiac arrhythmias, seizures and hypoglycemia. In the present case, no systemic complication occurred during ethanol injections. In some anatomic localizations, it is very difficult to treat hemangiomatous lesions because of bleeding and the risk of damaging the neighbouring anatomical structures. Percutaneous ethanol injection therapy is an alternative to conventional surgical resection in these cases. In the present case, percutaneous ethanol injection treatment increased the effectiveness of surgery and helped to achieve optimal aesthetic results without complication.

\section{REFERENCES}

1. Kane WJ, Morris S, Jackson IT, Woods JE. Significant hemangiomas and vascular malformations of the head and neck: Clinical management and treatment outcomes. Ann Plast Surg 1995;35:133-43. 
2. Doppman JL, Oldfield EH, Heiss JD. Symptomatic vertebral hemangiomas: Treatment by means of direct intralesional injection of ethanol. Radiology 2000;214:341-8.

3. Zuckerman DA, Yeager TD. Percutaneous ethanol sclerotherapy of postoperative lymphoceles. AJR Am J Roentgenol 1997;169:433-7.

4. Volk M, Rogler G, Strotzer M, Lock G, Manke C, Feuerbach S.

Post-traumatic pseudocyst of the spleen: Sclerotherapy with ethanol. Cardiovasc Intervent Radiol 1999;22:246-8.

5. Meirelles-Santos JO, Carvalho AF Jr, Callejas-Neto F, et al. Absolute ethanol and 5\% ethanolamine oleate are comparable for sclerotherapy of esophageal varices. Gastrointest Endosc 2000;51:573-6.

6. Asaki ST. Efficacy of endoscopic pure ethanol injection method for gastrointestinal ulcer bleeding. World J Surg 2000;24:294-8.

7. Yang YH, Lee PI, Lin KH, Tsang YM. Absolute ethanol embolotherapy for hemangioma with Kasabach-Merrit syndrome. Zhonghua Min Guo Xiao Er Ke Yi Xue Hui Za Zhi 1998;39:51-4.

8. Mason KP, Michna E, Zurakowski D, Koka BV, Burrows PE. Serum ethanol levels in children and adults after ethanol embolisation or sclerotherapy for vascular anomalies. Radiology 2000;217:127-32. 